\title{
The Sensed Presence Questionnaire (SenPQ): Initial psychometric validation of a measure of the "Sensed Presence" experience
}

\author{
Joseph M Barnby ${ }^{\text {Corresp., }}{ }^{1}$, Vaughan Bell ${ }^{1}$ \\ 1 Department of Psychiatry, University College London, University of London, London, United Kingdom \\ Corresponding Author: Joseph M Barnby \\ Email address: joseph.barnby@ucl.ac.uk
}

Background. The experience of 'sensed presence' - a feeling or sense that another entity, individual or being is present despite no clear sensory or perceptual evidence - is known to occur in the general population, appears more frequently in religious or spiritual contexts, and seems to be prominent in certain psychiatric or neurological conditions and may reflect specific functions of social cognition or body-image representation systems in the brain. Previous research has relied on ad-hoc measures of the experience and no specific psychometric scale to measure the experience exists to date.

Methods. Based on phenomenological description in the literature, we created the 16-item Sensed Presence Questionnaire (SenPQ). We recruited participants from i) a general population sample, and; ii) a sample including specific selection for religious affiliation, to complete the SenPQ and additional measures of well-being, schizotypy, social anxiety, social imagery, and spiritual experience. We completed an analysis to test internal reliability, the ability of the SenPQ to distinguish between religious and non-religious participants, and whether the SenPQ was specifically related to positive schizotypical experiences and social imagery. A factor analysis was also conducted to examine underlying latent variables.

Results. The SenPQ was found to be reliable and valid, with religious participants significantly endorsing more items than non-religious participants, and the scale showing a selective relationship with construct relevant measures. Principal components analysis indicates two potential underlying factors interpreted as reflecting 'benign' and 'malign' sensed presence experiences.

Discussion. The SenPQ appears to be a reliable and valid measure of sensed presence experience although further validation in neurological and psychiatric conditions is warranted. 
1 Full Title:

2 The Sensed Presence Questionnaire (SenPQ):

3 Initial Psychometric Validation of a Measure of the "Sensed Presence" Experience

4

5 Authors:

6 Joseph M Barnby $^{1 *}$, Vaughan Bell ${ }^{1}$

7

8 1. Division of Psychiatry, University College London, 6th Floor, Maple House, 149 Tottenham

9 Court Road, London, W1T 7NF, UK.

10

*Corresponding author:

12 Joseph M Barnby

13 Division of Psychiatry, University College London,

14 6th Floor, Maple House,

15149 Tottenham Court Road,

16 London W1T 7NF

17

18 Email: Joseph.Barnby@ucl.ac.uk

19 Tel: +44 (0)20 76792000

20 
Background. The experience of 'sensed presence' - a feeling or sense that another entity, individual or being is present despite no clear sensory or perceptual evidence - is known to occur in the general population, appears more frequently in religious or spiritual contexts, and seems to be prominent in certain psychiatric or neurological conditions and may reflect specific functions of social cognition or body-image representation systems in the brain. Previous research has relied on ad-hoc measures of the experience and no specific psychometric scale to measure the experience exists to date.

Methods. Based on phenomenological description in the literature, we created the 16 -item Sensed Presence Questionnaire (SenPQ). We recruited participants from i) a general population sample, and; ii) a sample including specific selection for religious affiliation, to complete the SenPQ and additional measures of well-being, schizotypy, social anxiety, social imagery, and spiritual experience. We completed an analysis to test internal reliability, the ability of the SenPQ to distinguish between religious and non-religious participants, and whether the SenPQ was specifically related to positive schizotypical experiences and social imagery. A factor analysis was also conducted to examine underlying latent variables.

Results. The SenPQ was found to be reliable and valid, with religious participants significantly endorsing more items than non-religious participants, and the scale showing a selective relationship with construct relevant measures. Principal components analysis indicates two potential underlying factors interpreted as reflecting 'benign' and 'malign' sensed presence experiences.

42 Discussion. The SenPQ appears to be a reliable and valid measure of sensed presence experience 43 although further validation in neurological and psychiatric conditions is warranted. 
45

46

47

48

49

\section{Introduction}

William James (1902) first attempted to understand the sensed presence experience

psychologically, describing the experience "as if there were in the human consciousness a sense of reality, a feeling of objective presence, a perception of what we may call 'something there"'. The philosopher and psychiatrist Karl Jaspers also discussed it in his influential book on the phenomenology of psychiatry, General Psychopathology, defining it as where "we are aware that something is present which at that moment is not based on any obvious sensory sign" (Jaspers, 1913 / 1963).

Contemporary researchers define the experience of sensed presence, sometimes called 'feeling of presence' or 'felt presence,' as the subjective experience of the presence of an external entity, being, or individual despite no clear sensory or perceptual evidence (Thompson, 1982; Cheyne, 2001; Blom, 2010; Luhrmann, 2012, 2013; Alderson-Day, 2016). This more recent research has reported that it is particularly prevalent in certain contexts and psychological states.

One area particularly associated with the sensed presence experience is spirituality and religion. Luhrmann and Morgain (2012) described how participants in a prayer group frequently described the experience of a 'near tangible presence', and Luhrmann's ethnographic work (summarised in Luhrmann, 2012) has noted how this experience forms an essential component of evangelical religious practice. Suedfeld and Mocellin (1987) described the role of intense physiological states in 'spirit quests' common in many traditional religious practices that specifically induce a sensed presence experience, and Granqvist et al. (2005) and Granqvist and Larsson (2006) have 
67 demonstrated experimentally that the experience can be induced by priming participants with

68 religious concepts.

69 However, the experience has also been reported in a range of other, neurophysiological contexts.

70 These include sleep-related hallucinations and paralysis, where it is typically associated with fear

71 and anxiety (Cheyne et al., 1999), epileptic seizure (Landtblom, 2006) and particularly temporal

72 lobe epilepsy (Trimble \& Freeman, 2006), psychoactive drug use (Barbosa et al., 2005), and

73 direct brain stimulation (Arzy \& Schurr, 2016); and has been associated with psychosis and

74 auditory hallucinations (Woods et al., 2015), acquired brain injury (Brugger et al., 1996),

75 Parkinson's disease (Fenelon et al., 2011), and a range of intense emotional or physiological

76 states (Suedfeld \& Mocellin, 1987) including bereavement (Steffan \& Coyle, 2011).

Previous theories have suggested the sensed presence phenomenon may be a result of a projected 79 internal body map (Brugger et al., 1996), partial activation of the threat system (Cheyne \&

80 Girard, 2007), or a form of externalised social imagery (Nielsen, 2007; Solomonova et al., 2008),

81 or, perhaps more exotically, an external projection of autonomous unconscious processes

82 (Jaynes, 2000; Jung, 1969).

83

84 Notably, neuropsychological theories have been based on increasing numbers of studies where

85 the experience has been induced in the lab, or reported in observational or patient studies, but it

86 is noteworthy that no specific psychometric measure for the sensed presence experience exists

87 and current studies rely on scales which are not ideally suited to the task or simple verbal

88 description. 
90 A seven item subscale of the Other Experiences Questionnaire (OEQ7) (Nielsen, cited in

91 Solomonova et al., 2008) has been used to measure experiences akin to sensed presence

92 experience in previous studies (Solomonova et al., 2008). However, the OEQ7 is actually

93 intended to measure 'social imagery', and includes items on imaginary companions, seeing

94 apparitions, and the feeling of being followed, alongside items on the actual sensed presence

95 experience.

97 Trimble and Freeman (2006) measured sensed presence in religious and non-religious

98 individuals with epilepsy by using items from the Index of Core Spiritual Experiences

99 (INSPIRIT) questionnaire (Kass et al., 1991). However, as the study used selected items from a

100 specific spirituality questionnaire, this would not be suitable for measuring sensed presence 101 experiences in other contexts.

102

103 Other scales include the sensed presence experience but only as a single item - such as the

104 Tellegen Absorption Scale (Tellegen and Atkinson, 1974), the Magical Ideation Scale (Eckblad 105 and Chapman, 1983), and the Cardiff Anomalous Perceptions Scale (Bell et al., 2006).

Alternatively, some studies have simply asked people to affirm whether they have had a sensed presence experience. For example, while Hay (1979) reported useful descriptive themes of SP experiences from participants, Hay (1979) and Hay and Morisy (1978) did not use comprehensive or validated measures to capture SP experiences and simply relied on a single 111 question. 
113 Given the potential for sensed presence experiences to provide a window into

114 neuropsychological mechanisms for body representation or social cognition, clearly, a robust and

115 validated measure of the phenomena is needed.

116 With this in mind, we created and investigated the reliability and validity of a new scale, called

117 the 'Sensed Presence Questionnaire' (SenPQ), designed to capture the experience of 'sensed

118 presence' in a psychometrically robust manner.

119

120 As religious practice has been traditionally associated with greater levels of sensed presence 121 experience, as part of the scale validation we predicted that individuals who have religious

122 practice / belief from the general population would score higher on the SenPQ as people without.

123 Based on previous research, we also predicted that the SenPQ would selectively correlate with

124 measures of unusual perceptual experiences but no other aspects of schizotypy, as well as

125 correlating with measures of social imagery and daily spiritual experience.

126

\section{Materials and Methods}

128 A cross-sectional observational design was used in the general population. Data was collected in

129 the form of an online survey using two distinct samples. The study was reviewed and ethically

130 approved by the UCL ethics review board (ref no.: 8587/001). Participants indicated consent on

131 the online form.

132

Design of the Sensed Presence Questionnaire (SenPQ)

134 The Sensed Presence Questionnaire (SenPQ) comprises of 16 questions. These were derived

135 from a literature review of the sensed presence phenomenon spanning studies from sleep 
136 paralysis, epilepsy and other neurological disorders, psychosis, stress and anxiety, ritual, drug

137 induced experiences, and the general population. As well as covering a range of typical sensed

138 presence experiences from the scientific literature, the scale also includes items that are

139 positively and negatively valenced, as well as neutrally valenced in their presentation.

141 The questionnaire requests that respondents refer to experiences from the last month only when

142 rating the items, and not to record any perceptions associated with drug-induced experiences.

143 Respondents are asked to indicate the frequency with which the experience has occurred using a

144 Likert-like scale: 'Never', 'Occasionally', 'Sometimes', 'Very Often', 'Always'. The

145 questionnaire is freely available online and has been released under a Creative Commons license

146 at the following link: https://osf.io/fecgz/

Participants

149 Participants were recruited via two methods: i) online via the http://proflic.ac online study

150 recruitment platform that has diverse participant base and where we received 101 completed

151 responses from separate individuals (Sample S1) from 135 responses in total including

152 incomplete responses. In addition, social media advertisements were sent from the authors'

153 personal accounts and accounts associated with the authors' university department (with notices

154 that did not refer to anything spiritual or religious) and emails were sent to religious groups

155 including university religious societies (Hindu society, Islamic Society, Christian Union, Sikh

156 Society, Buddhist Society, and the Jewish Society) and local churches requesting participants

157 (Sample S2). Recruitment for both samples was started in parallel. The questionnaire took

158 approximately 25 minutes to complete. Participants recruited via the online recruitment service 
159 were paid $£ 4$ upon questionnaire completion. All participants were directed to the same online 160 questionnaires.

161

162 Individuals who clicked on the link to the survey and began to fill in the survey were considered

163 to have been recruited into the study, regardless of whether the scales were fully completed,

164 although only complete questionnaire sets were entered into the analysis. Questionnaires were

165 preceded by a page requesting demographic data that required age, gender, religious belief, 166 average meditation practice, ethnic group, and education level.

167

Both samples were combined for the final analysis which consisted of a total of 191 participants

included (see Figure 1). Analysis scripts that conduct a separate analysis for each sample (minus the principal components analysis which is underpowered when not conducted on the whole

171 sample) are available on the Open Science Framework page for this study (https://osf.io/fecgz/),

172 which demonstrate the same pattern of results in each sample, supporting the reliability and

173 validity of the scale. 


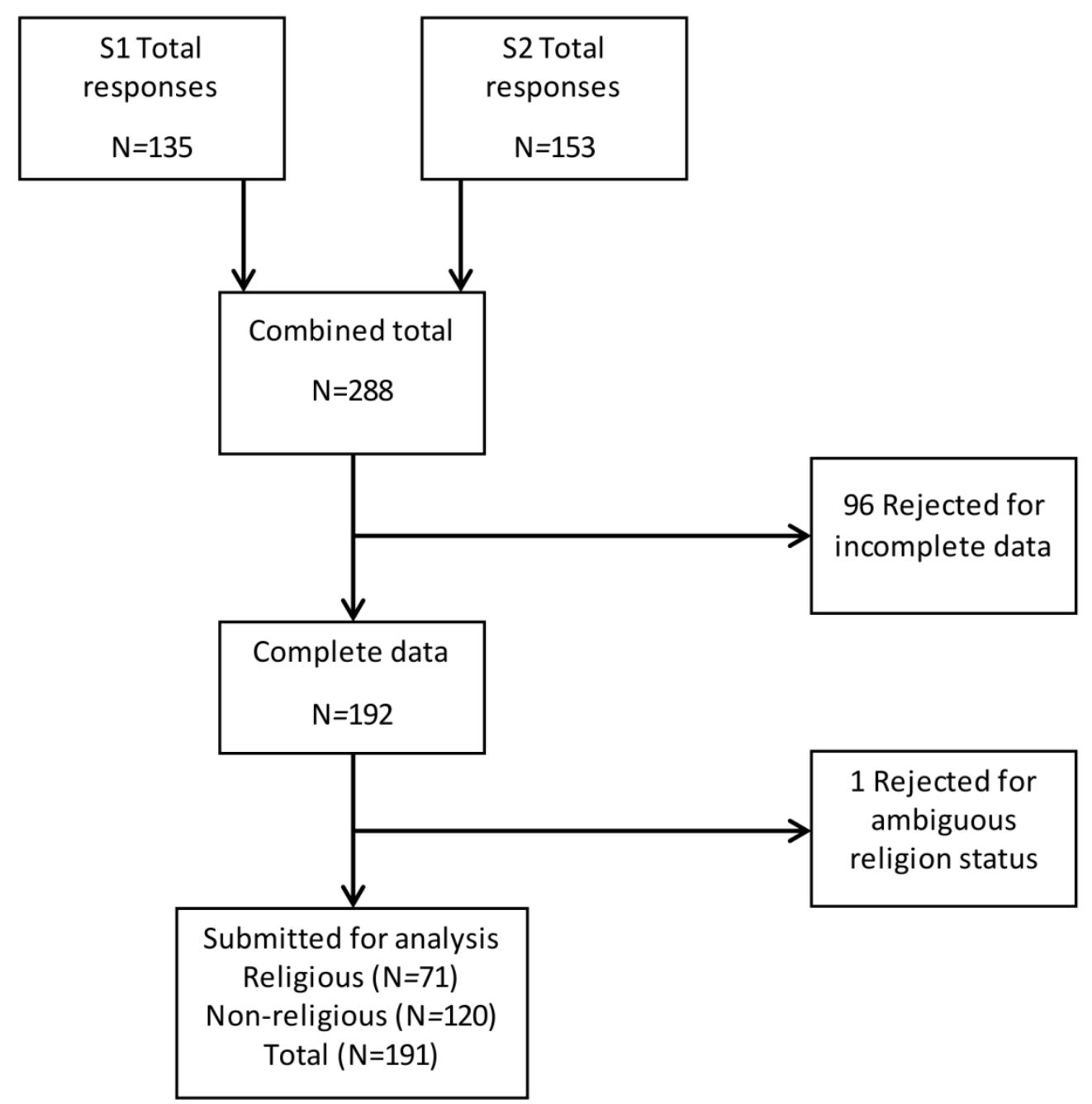

Figure 1 - Recruitment diagram

178 Other Experiences Questionnaire - social imagery subscale (OEQ7) (Solomonova et al., 2008): a

179 validated subscale designed to capture social imagery, and has previously been established as

180 reliable and valid in the context of sleep paralysis and anxiety. The frequency of each item is

181 rated on a 4-point Likert scale. This measure has been previously used to measure an aspect of 
182 the sensed presence experience, and we predicted that it would correlate with SenPQ scores,

183 indicating convergent validity. The internal reliability for the scale in this study, measured using

184 Cronbach's Alpha, was 0.706

185

186

Brief Oxford-Liverpool Inventory of Feeling and Experiences (O-LIFE) (Mason et al., 2005): a

briefer, validated version of the O-LIFE schizotypy scale (Claridge et al., 1996) that includes

four subscales that measure different aspects of schizotypy: unusual experiences (UE), cognitive disorganisation (CD), introvertive anhedonia (IA), and impulsive non-conformity (IN). Each item is rated on a binary scale, with participants either affirming or disagreeing with each statement. We predicted a selective association between the SenPQ and the unusual experiences subscale of the O-LIFE, indicating that the sensed presence experience reflected a form of reality distortion experience but no other cognitive or behavioural aspects of schizotypy. Internal reliability of the scale in this study was 0.863

Daily Spiritual Experience Scale (DSES) (Underwood \& Teresi, 2002) is originally a 16-item validated scale designed to assess spiritual experiences in daily life. This scale was based on qualitative research and has been tested for reliability and validity in a range of populations (Underwood, 2011). The first 15 items are answered on a 6-point Likert scale that ask about frequency of particular spiritual experiences from 'many times a day' to 'never or almost never'. The final item is a general question about 'how close do you feel to God' and is answered on a four point Likert scale from 'not close at all' to 'as close as possible'. This item was omitted as it has been found not to be reliable for some Hindu and Muslim respondents (Husain et al, 2016) who were groups we specifically invited to participate. However, the DSES has been shown to 
205 be reliable and valid in this 15-item form (Kim et al., 2016; Kurian et al., 2016). Considering that

206 the sensed presence experience has been reportedly more frequently in spiritual and religious

207 contexts, we predicted a positive correlation with the SenPQ. Internal reliability of the scale in

208 this study was 0.936

209

210 We also included two scales that measured general psychological well-being and social

211 interaction anxiety for an exploratory analysis and use as potential covariates, given that sensed

212 presence experience has been previously associated with psychopathology in some populations.

213

214 WHO-5 Well-Being Index (World Health Organisation, 1998): a brief, validated well-being

215 questionnaire, shown to capture well-being as accurately as its extended version (Topp et al.,

216 2015). Each item describes an aspect of well-being and the respondent is asked rate how present

217 it has been during the last two on a 6-point Likert scale ranging from 'all of the time' to 'at no

218 time'. Internal reliability of the scale in this study was 0.844

219

220 The Social Interaction Anxiety Scale (SIAS) (Mattick \& Clarke, 1998): a validated scale

221 designed to capture anxiety associated with meeting, conversing, or mixing with others. Each

222 item describes anxiety associated with a particular social interaction scenario and the respondent

223 is asked to rate each item on a 5-point Likert scale from 'not at all' to 'extremely'. Internal

224 reliability of the scale in this study was 0.950

225 
226 Participants were also given the option of a free text box at the end of the questionnaire series to

227 describe a sensed presence experience in their own words if they indicated they had experienced 228 one. This information was not used in the current study. 
231 Analysis

232 Internal reliability of the SenPQ was tested with Cronbach's Alpha (Cronbach, 1951). Validity

233 was determined firstly by whether SenPQ score distinguished between religious and non-

234 religious groups by using an independent samples t-test, and we predicted a significant difference

235 between SenPQ in religious and non-religious groups, indicating discriminant validity. Secondly

236 we examined the association between SenPQ score and additional measures, predicting that the

237 SenPQ would selectively correlate with the O-LIFE unusual experiences subscale, the OEQ7

238 measure of social imagery and the DSES measure of spiritual experience, indicating convergent

239 and divergent validity. We had no specific predictions about associations with the measures of

240 anxiety and well-being, as sensed presence experiences have been previously associated with a

241 range of affective states (Alderson-Day, 2016).

242

243 In addition, we completed an exploratory principal components analysis of the SenPQ items on

244 the entire sample using direct oblimin rotation based on the assumption that underlying factors

245 would not be independent. The mean item scores for each individual factor loading were used for

246 all subsequent analysis. Parallel analysis for principle components $(95 \%$ confidence interval,

2471000 random correlation matrices) (Horn, 1965; O’Connor, 2000) and observation of the scree

248 plot (Cattell, 1966) were used to select retained factors. Subsequent factor analyses were

249 completed to specifically extract models for specific numbers of retained factors.

251 An Item Response Theory (IRT) analysis was performed on the entire dataset for scores on the

252 SenPQ. IRT is a model-based theory that measures the responses between items and the trait that

253 each item is supposedly measuring (Emberston \& Reise, 2000) - in this case, the sensitivity to 
254 sensed presence experiences. A Graded Response Model (GRM; Samejema, 1969) was used in

255 this particular IRT analysis - this is due to the SenPQ using a polytomous scoring system. The

256 GRM model attributes each item as a series of response dichotomies, or thresholds $(\beta)$ compared

257 to the discrimination parameter, or slope $(\alpha)$ - because the SenPQ items comprised 5 graded

258 choices (1- Never to 5- Always) this represents four $\beta$ : 1 vs $2-5\left(\beta_{1}\right), 1-2$ vs. 3-5 ( $\left.\beta_{2}\right), 1-3$ vs. 4-5

$259\left(\beta_{3}\right)$, and 1-4 vs. $5\left(\beta_{4}\right)$. These thresholds correspond to the trait level $(\theta)$ at which a new

260 individual answering the questionnaire has a 50\% chance of endorsing the relevant or higher

261 response. These thresholds are not the same for each item, and each item will have its own set of

262 thresholds.

263

264 Graphical illustrations of this relationship were also created. An Item Information Function (IIF),

265 Test Information Function (TIF), and Test Characteristic Curve (TCC) was generated for the

266 SenPQ. An IIF displays at which locations along the trait scale each item is able to be accurate

267 about a new individual using the questionnaire. A TIF reports the level of precision of the entire

268 measure at different points along the trait scale. A TCC shows the expected score of the measure

269 at different points along the trait scale.

270

271 We also completed a receiver operating characteristic (ROC) analysis to examine how specific

272 scale scores distinguished between religious and non-religious groups to additionally test

273 discriminant validity across the range of the measure.

274

275

276 


\section{Results}

281

282 283

\begin{tabular}{ll}
\hline & Frequency (\%) \\
\hline Religious Affiliation & \\
No Religion & $99(51.83)$ \\
Agnostic & $16(8.37)$ \\
Christian & $45(23.56)$ \\
Buddhist & $4(2.09)$ \\
Hindu & $2(1.04)$ \\
Jewish & $3(1.57)$ \\
Muslim & $3(1.57)$ \\
Sikh & $3(1.57)$ \\
Other & $16(8.37)$ \\
\hline Highest Level of Education & \\
GCSE & $10(5.23)$ \\
A Level & $29(15.18)$ \\
University Undergraduate & $93(48.69)$ \\
University Postgraduate & $59(30.89)$ \\
\hline
\end{tabular}

Demographics

The total sample consisted of 89 males, 99 females, 2 who selected 'Other' and 1 who selected 'Prefer not to say'. The mean age of the sample was 36.23 (SD = 13.4; Range $17-73$ ). Religious affiliation, ethnicity and level of education are reported in Table 1. For the purposes of classifying people into religious and non-religious groups for further analysis, people who selected 'No Religion' or 'Agnostic' were considered non-religious, as were individuals who recorded themselves as 'Atheist' under the 'Other' option. All others were considered religious. 
29220 participants reported daily meditation practice, 10 weekly practice, 23 monthly practice, and 293138 no practice. Self-reported ethnicity of the sample was "English / Welsh / Scottish / Northern 294 Irish / British" (N=131), "White other" $(\mathrm{N}=25)$, "Indian" $(\mathrm{N}=8)$, "White and Asian" $(\mathrm{N}=5)$, 295 "Chinese" $(\mathrm{N}=4)$, "White and Black African" $(\mathrm{N}=3)$, "Pakistani" $(\mathrm{N}=2)$, "Other" $(\mathrm{N}=2)$, "Irish"

296 (N=2), "White and Black Caribbean" $(\mathrm{N}=2)$, "Other Mixed / Multiple ethnic background" $(\mathrm{N}=2)$,

297 “Bangladeshi” ( $\mathrm{N}=1)$, “African” $(\mathrm{N}=1)$, “Caribbean” $(\mathrm{N}=1)$, “Arab” $(\mathrm{N}=1)$, “Gypsy or Irish 298 Traveller" $(\mathrm{N}=1)$.

Statistical analysis

301 Due to the sampling distribution of mean scores on the SenPQ violating the assumption of 302 normal distribution, all analyses were conducted using a simple bootstrap re-sampling method 303 (1000 samples, 95\% CI) (Bland \& Altman, 2015). All data analysis used SPSS v.22 (SPSS Inc.), 304 except for the IRT analysis which used STATA v.14 (Stata Corp). The raw data and analysis 305 scripts for this study are freely available online at the Open Science Framework at the following 306 link: https://osf.io/fecgz/

Internal reliability

All SenPQ items where entered into internal reliability analysis and the scale demonstrated very high internal consistency (Cronbach's alpha $=0.951)$.

\section{Validity}

313 Means and standard deviations for the scale scores are displayed in Table 2. Discriminant

314 validity of the SenPQ was demonstrated by conducting an independent samples t-test (two- 
315 tailed) between mean scores from religious $(\mathrm{N}=71)$ and non-religious groups $(\mathrm{N}=120)$. The

316 religious group had a higher mean score than the non-religious group (see Table 2), a difference

317 which was significant when tested with an independent samples $\mathrm{t}$-test $(\mathrm{t}=-3.592, p=0.002$,

318 mean difference $=-5.208,95 \% \mathrm{CI}:-8.098--2.156$; Cohen's $\mathrm{d}=0.51)$, indicating good

319 discriminant validity.

320

321 As can be seen in Table 3, the SenPQ demonstrated a strong significant correlation with the

322 OEQ-7 social imagery scale and a moderate significant correlation with the DSES daily spiritual 323 experiences scale. There was a strong significant correlation with the unusual experiences

324 subscale of the O-LIFE schizotypy scale, a weak correlation with the impulsive non-conformity

325 subscale, and no significant correlation with the cognitive disorganisation or introvertive

326 anhedonia subscales, indicating good convergent and divergent validity. 


\begin{tabular}{|c|c|c|c|c|c|c|c|c|c|c|c|c|c|c|c|}
\hline \multirow[b]{2}{*}{ Group } & \multirow[b]{2}{*}{$N$} & \multirow[b]{2}{*}{ Age } & \multirow{2}{*}{$\begin{array}{c}\text { Gender } \\
(M: F: O)\end{array}$} & \multirow[b]{2}{*}{ SenPQ } & \multirow[b]{2}{*}{$\begin{array}{c}\text { BSen } \\
\text { PQ }\end{array}$} & \multirow[b]{2}{*}{$\begin{array}{c}\text { MSen } \\
\text { PQ }\end{array}$} & \multirow[b]{2}{*}{ OEQ7 } & \multicolumn{5}{|c|}{$O-L I F E$} & \multirow[b]{2}{*}{$D S E S$} & \multirow[b]{2}{*}{$\begin{array}{c}\text { WHO } \\
-5\end{array}$} & \multirow[b]{2}{*}{$S I A S$} \\
\hline & & & & & & & & Total & $U E$ & $C D$ & $I A$ & $I N$ & & & \\
\hline Religious & 71 & $\begin{array}{c}36.20 \\
(13.04)\end{array}$ & $35: 35: 1$ & $\begin{array}{c}26.55 \\
(11.86)\end{array}$ & $\begin{array}{l}15.35 \\
(7.43)\end{array}$ & $\begin{array}{l}12.93 \\
(5.67)\end{array}$ & $\begin{array}{l}10.85 \\
(2.94)\end{array}$ & $\begin{array}{l}14.42 \\
(7.73)\end{array}$ & $\begin{array}{c}4.14 \\
(3.20)\end{array}$ & $\begin{array}{c}4.24 \\
(2.83)\end{array}$ & $\begin{array}{c}2.80 \\
(1.98)\end{array}$ & $\begin{array}{c}3.24 \\
(2.08)\end{array}$ & $\begin{array}{c}44.93 \\
(15.60)\end{array}$ & $\begin{array}{l}19.97 \\
(4.29)\end{array}$ & $\begin{array}{c}46.13 \\
(14.22)\end{array}$ \\
\hline $\begin{array}{c}\text { Non- } \\
\text { Religious }\end{array}$ & 120 & $\begin{array}{c}36.25 \\
(13.66)\end{array}$ & $54: 64: 2$ & $\begin{array}{l}21.34 \\
(8.14)\end{array}$ & $\begin{array}{l}11.57 \\
(4.86)\end{array}$ & $\begin{array}{l}11.17 \\
(4.44)\end{array}$ & $\begin{array}{c}9.34 \\
(2.65)\end{array}$ & $\begin{array}{l}14.47 \\
(7.47)\end{array}$ & $\begin{array}{c}3.12 \\
(2.77)\end{array}$ & $\begin{array}{c}4.62 \\
(2.96)\end{array}$ & $\begin{array}{c}3.22 \\
(2.39)\end{array}$ & $\begin{array}{c}3.51 \\
(2.33)\end{array}$ & $\begin{array}{c}30.28 \\
(11.48)\end{array}$ & $\begin{array}{l}19.34 \\
(4.58)\end{array}$ & $\begin{array}{c}49.59 \\
(17.83)\end{array}$ \\
\hline Total & 191 & $\begin{array}{c}36.23 \\
(13.40)\end{array}$ & $89: 99: 3$ & $\begin{array}{l}23.28 \\
(9.98)\end{array}$ & $\begin{array}{l}12.97 \\
(6.21)\end{array}$ & $\begin{array}{c}11.82 \\
(5)\end{array}$ & $\begin{array}{c}9.90 \\
(2.84)\end{array}$ & $\begin{array}{l}14.45 \\
(7.55)\end{array}$ & $\begin{array}{c}3.50 \\
(2.97)\end{array}$ & $\begin{array}{c}4.48 \\
(2.91)\end{array}$ & $\begin{array}{c}3.07 \\
(2.25)\end{array}$ & $\begin{array}{c}3.41 \\
(2.24)\end{array}$ & $\begin{array}{c}35.72 \\
(14.92)\end{array}$ & $\begin{array}{l}19.58 \\
(4.48)\end{array}$ & $\begin{array}{c}48.30 \\
(16.62)\end{array}$ \\
\hline
\end{tabular}

328

Table 2 - Descriptive statistics for the religious, non-religious, and total samples.

330 Legend: SenPQ=Sensed Presence Questionnaire, $\mathrm{BSenPQ}=$ Benign Sensed Presence Questionnaire factor items, $\mathrm{MSenPQ}=\mathrm{Malign}$ Sensed

331 Presence Questionnaire factor items, O-LIFE = brief Oxford-Liverpool Inventory of Feelings and Experiences, UE = Unusual Experiences subset,

$332 \mathrm{CD}=$ Cognitive Disorganisation subset, IA = Introvertive Anhedonia subset, IN = Impulsive Non-Conformity subset, OEQ-7 = Other Experiences

333 Questionnaire, WHO-5 = World Health Organisation 5-item well-being questionnaire, DSES = Daily Spiritual Experience Scale, SIAS = Social

334 Interaction Anxiety Scale. 


\begin{tabular}{|c|c|c|c|c|c|c|c|c|c|}
\hline & \multicolumn{5}{|c|}{$O-L I F E$} & \multirow[b]{2}{*}{$O E Q-7$} & \multirow[b]{2}{*}{ WHO-5 } & \multirow[b]{2}{*}{ DSES } & \multirow[b]{2}{*}{ SIAS } \\
\hline & $U E$ & $C D$ & $I A$ & $I N$ & Total & & & & \\
\hline $\operatorname{Sen} P Q$ & $0.641 * * *$ & 0.110 & 0.068 & $0.308 * * *$ & $0.406 * * *$ & $0.673 * * *$ & 0.056 & $0.407 * * *$ & 0.025 \\
\hline
\end{tabular}

336

337 Table 3 - Pearson correlations between SenPQ and other scales in the total sample.

Legend: SenPQ=Sensed Presence Questionnaire, O-LIFE = brief Oxford-Liverpool Inventory of Feelings and Experiences, UE = O-LIFE Unusual

Experiences subscale, $\mathrm{CD}=\mathrm{O}$-LIFE Cognitive Disorganisation subscale, IA = O-LIFE Introvertive Anhedonia subscale, $\mathrm{O}$-LIFE IN $=$ Impulsive

Non-Conformity subscale, OEQ-7 = Other Experiences Questionnaire, WHO-5 =World Health Organisation 5-item well-being questionnaire,

342 DSES = Daily Spiritual Experience Scale, SIAS = Social Interaction Anxiety Scale. ${ }^{* * *} \mathrm{p}<0.001$. 
344 Demographic analysis

345 No significant correlation between the age and SenPQ score (Pearson $r=0.026, p=0.723)$ was

346 found and no significant difference between genders when tested with an independent samples t-

347 test $(\mathrm{t}=1.268, \mathrm{p}=0.206)$. There was no significant effect of education level on SenPQ score

348 when tested with a one-way between subject $\operatorname{ANOVA}\left(\mathrm{F}_{(3,187)}=1.100, \mathrm{p}=0.350\right)$. Because so

349 few people reported meditation practice at the more frequent end of practice, this was collapsed

350 into a binary 'yes / no' variable. People who reported engaging with any sort of meditation

351 practice were significantly more likely to score higher on the SenPQ when tested with an

352 independent samples t-test $(\mathrm{t}=3.222, \mathrm{p}=0.001)$.

353

354 Measures of anxiety and well-being

355 No significant associations were found between the SenPQ and WHO-5 score $(r=.56, p=.443)$

356 and between the SenPQ and SIAS score $(r=.025, \mathrm{p}=.773)$.

357

358 Factor analysis of the SenPQ

359 To investigate the factor loadings of the Sensed Presence Questionnaire, a factor analysis was

360 run on all 16 items.

361

362 To test assumptions, a Kaiser-Meyer-Olkin measure of sampling adequacy (0.925) and

363 Bartlett's test of sphericity $[\chi 2(120)=2467.009, \mathrm{p}<0.001]$ were run and considered adequate,

364 with all items significantly correlating by at least $0.3(\mathrm{p}<0.001)$. 
366 An initial factor analysis suggested a two factor solution based on inspection of the scree plot

367 that indicated a clear break after two components (Cattell, 1966). The parallel analysis conducted

368 using O'Connor's (2000) method suggested a one factor solution, based on the fact that only one

369 eigenvalue from the study data set was greater than the simulated equivalent for randomly

370 generated correlation matrices, with the second factor being marginally below the cut-off. We

371 subsequently conducted two separate factor analyses that specifically extracted one and two

372 component solutions and subsequently judged the two component solution to be more

373 interpretable. The first factor was interpreted as 'benign presence' and the second factor was

374 interpreted as 'malign presence'. The first component explained $52.28 \%$ of the variance, and the

375 second component explained an additional $7.66 \%$ of the variance in the sample. The pattern

376 matrix can be found in Table 4. 


\begin{tabular}{|c|c|c|c|}
\hline & Item & Factor 1 & Factor 2 \\
\hline 13 & $\begin{array}{l}\text { I have felt the presence of a protective being around me that I } \\
\text { couldn't see }\end{array}$ & 0.990 & \\
\hline 6 & $\begin{array}{l}\text { I have felt I was being watched over by caring being that I } \\
\text { couldn't see }\end{array}$ & 0.981 & \\
\hline 3 & $\begin{array}{l}\text { When I was under a lot of pressure, I felt someone or } \\
\text { something was accompanying me }\end{array}$ & 0.823 & \\
\hline 8 & I have felt when an unseen presence has arrived & 0.707 & \\
\hline 5 & $\begin{array}{l}\text { During times of stress I have had the feeling that I was being } \\
\text { accompanied by an unseen presence }\end{array}$ & 0.604 & \\
\hline 11 & $\begin{array}{l}\text { I have visited certain places where I can feel the presence of } \\
\text { distinct but unseen beings }\end{array}$ & 0.581 & \\
\hline 12 & $\begin{array}{l}\text { I can feel the presence of people that I know are physically } \\
\text { distant from me }\end{array}$ & 0.559 & \\
\hline 15 & $\begin{array}{l}\text { Even though I knew the person had died, I felt them } \\
\text { accompanying me }\end{array}$ & 0.550 & \\
\hline 7 & $\begin{array}{l}\text { When I have visited specific locations, I felt I was in the } \\
\text { presence of an unseen being or beings }\end{array}$ & 0.494 & 0.432 \\
\hline 1 & $\begin{array}{l}\text { I have felt another being or beings near me when I couldn't see } \\
\text { anyone around me that could explain it }\end{array}$ & & 0.544 \\
\hline 10 & $\begin{array}{l}\text { I have felt as if someone or something is near me, even though I } \\
\text { know it is not really the case }\end{array}$ & & 0.578 \\
\hline 2 & $\begin{array}{l}\text { When half asleep I have thought someone else was with me, } \\
\text { only to find out when I woke up that they couldn't have been }\end{array}$ & & 0.693 \\
\hline 16 & $\begin{array}{l}\text { Even though I knew it was my imagination, I still felt as if } \\
\text { someone or something was with me }\end{array}$ & & 0.701 \\
\hline 9 & $\begin{array}{l}\text { I have woken up during the night with the feeling that an } \\
\text { unseen presence was in the room with me }\end{array}$ & & 0.702 \\
\hline 14 & $\begin{array}{l}\text { I have felt a sinister or threatening presence around me, despite } \\
\text { not being able to see any evidence for it }\end{array}$ & & 0.822 \\
\hline 4 & $\begin{array}{l}\text { I have had the feeling that a negative or hurtful presence was } \\
\text { around me that I couldn't see }\end{array}$ & & 0.896 \\
\hline
\end{tabular}


381 Legend: All loadings less than 0.4 are not displayed.

382 Item-Response Theory Graded Response Modelling

383 The SenPQ was submitted to an IRT GRM bootstrap analysis (1000 replications) to understand

384 the relationship between difficulty of items and sensitivity to sensed presence experiences.

385 The analysis reported that all items had moderate to large slopes $(\alpha=1.76-4.51)$ with a model

$386 \log$ likelihood value of -1947.92. All $\beta$ values were evenly spaced and ascending from $\beta_{1}$ to $\beta_{4}$.

387 Two $\beta_{4}$ thresholds were not available because no participant answered '5-Always' on item 3 and

388 7: 'When I was under a lot of pressure, I felt someone or something was accompanying me', and

389 'When I have visited specific locations, I felt I was in the presence of an unseen being or beings', 390 respectively.

391 Table 5 shows the results for the slopes $(\alpha)$ and threshold parameters $(\beta 1-\beta 4)$ for all items on the 392 SenPQ.

393 Observing the slopes and the residuals suggests that all items were providing high item level and 394 test level information, with item 9 being the 'easiest', and item 5 the 'hardest'.

395 Residuals at the test and item level were also analysed graphically. Figure 2 displays the IIF, 396 TIF, and TCC for the SenPQ.

397 Because a large portion of the curves are above $0 \theta$ in figure 2, this suggests that the SenPQ is 398 better designed for respondents with higher sensitivity to sensed presence experiences. 


\begin{tabular}{|c|c|c|c|c|c|}
\hline Items & $\alpha$ & $\beta_{1}$ & $\beta_{2}$ & $\beta_{3}$ & $\beta_{4}$ \\
\hline 1 & $\begin{array}{c}3.12 \\
(0.52)\end{array}$ & $\begin{array}{c}0.61 \\
(0.11)\end{array}$ & $\begin{array}{c}1.56 \\
(0.15)\end{array}$ & $\begin{array}{c}2.22 \\
(0.21)\end{array}$ & $\begin{array}{c}2.88 \\
(0.25)\end{array}$ \\
\hline 2 & $\begin{array}{c}1.97 \\
(0.29)\end{array}$ & $\begin{array}{c}0.36 \\
(0.12)\end{array}$ & $\begin{array}{c}1.32 \\
(0.16)\end{array}$ & $\begin{array}{c}2.31 \\
(0.29)\end{array}$ & $\begin{array}{c}3.51 \\
(0.41)\end{array}$ \\
\hline 3 & $\begin{array}{c}3.40 \\
(0.57)\end{array}$ & $\begin{array}{c}0.71 \\
(0.1)\end{array}$ & $\begin{array}{c}1.40 \\
(0.14)\end{array}$ & $\begin{array}{c}1.97 \\
(0.18)\end{array}$ & $*$ \\
\hline 4 & $\begin{array}{c}2.45 \\
(0.33)\end{array}$ & $\begin{array}{c}0.92 \\
(0.14)\end{array}$ & $\begin{array}{c}1.67 \\
(0.18)\end{array}$ & $\begin{array}{c}2.61 \\
(0.27)\end{array}$ & $\begin{array}{c}3.09 \\
(0.34)\end{array}$ \\
\hline 5 & $\begin{array}{c}4.51 \\
(0.98)\end{array}$ & $\begin{array}{c}0.71 \\
(0.11)\end{array}$ & $\begin{array}{c}1.26 \\
(0.13)\end{array}$ & $\begin{array}{c}1.83 \\
(0.16)\end{array}$ & $\begin{array}{c}2.56 \\
(0.23)\end{array}$ \\
\hline 6 & $\begin{array}{c}2.75 \\
(0.42)\end{array}$ & $\begin{array}{c}0.60 \\
(0.11)\end{array}$ & $\begin{array}{c}1.33 \\
(0.13)\end{array}$ & $\begin{array}{c}2.01 \\
(0.18)\end{array}$ & $\begin{array}{c}2.72 \\
(0.26)\end{array}$ \\
\hline 7 & $\begin{array}{c}3.81 \\
(0.55)\end{array}$ & $\begin{array}{l}0.51 \\
(0.1)\end{array}$ & $\begin{array}{c}1.14 \\
(0.12)\end{array}$ & $\begin{array}{c}1.80 \\
(0.13)\end{array}$ & $*$ \\
\hline 8 & $\begin{array}{c}2.93 \\
(0.45)\end{array}$ & $\begin{array}{c}0.95 \\
(0.13)\end{array}$ & $\begin{array}{c}1.51 \\
(0.15)\end{array}$ & $\begin{array}{c}1.89 \\
(0.19)\end{array}$ & $\begin{array}{c}2.47 \\
(0.28)\end{array}$ \\
\hline 9 & $\begin{array}{c}1.76 \\
(0.32)\end{array}$ & $\begin{array}{c}0.54 \\
(0.14)\end{array}$ & $\begin{array}{c}1.42 \\
(0.20)\end{array}$ & $\begin{array}{c}2.50 \\
(0.40)\end{array}$ & $\begin{array}{c}3.74 \\
(0.54)\end{array}$ \\
\hline 10 & $\begin{array}{c}3.14 \\
(0.48)\end{array}$ & $\begin{array}{c}0.35 \\
(0.09)\end{array}$ & $\begin{array}{c}1.26 \\
(0.15)\end{array}$ & $\begin{array}{l}2.17 \\
(0.2)\end{array}$ & $\begin{array}{c}2.89 \\
(0.23)\end{array}$ \\
\hline 11 & $\begin{array}{c}4.36 \\
(0.69)\end{array}$ & $\begin{array}{l}0.56 \\
(0.1)\end{array}$ & $\begin{array}{c}1.31 \\
(0.12)\end{array}$ & $\begin{array}{c}1.85 \\
(0.15)\end{array}$ & $\begin{array}{l}2.64 \\
(0.2)\end{array}$ \\
\hline 12 & $\begin{array}{c}2.13 \\
(0.39)\end{array}$ & $\begin{array}{c}0.86 \\
(0.15)\end{array}$ & $\begin{array}{c}1.60 \\
(0.20)\end{array}$ & $\begin{array}{c}2.19 \\
(0.24)\end{array}$ & $\begin{array}{c}2.87 \\
(0.33)\end{array}$ \\
\hline 13 & $\begin{array}{c}3.33 \\
(0.56)\end{array}$ & $\begin{array}{c}0.75 \\
(0.12)\end{array}$ & $\begin{array}{c}1.37 \\
(0.12)\end{array}$ & $\begin{array}{c}1.89 \\
(0.15)\end{array}$ & $\begin{array}{c}2.38 \\
(0.23)\end{array}$ \\
\hline 14 & $\begin{array}{c}2.12 \\
(0.38)\end{array}$ & $\begin{array}{c}0.97 \\
(0.14)\end{array}$ & $\begin{array}{c}1.94 \\
(0.25)\end{array}$ & $\begin{array}{c}2.52 \\
(0.31)\end{array}$ & $\begin{array}{c}3.04 \\
(0.38)\end{array}$ \\
\hline 15 & $\begin{array}{c}2.31 \\
(0.38)\end{array}$ & $\begin{array}{c}0.78 \\
(0.12)\end{array}$ & $\begin{array}{c}1.52 \\
(0.19)\end{array}$ & $\begin{array}{c}2.29 \\
(0.31)\end{array}$ & $\begin{array}{c}3.23 \\
(0.38)\end{array}$ \\
\hline 16 & $\begin{array}{c}2.91 \\
(0.46)\end{array}$ & $\begin{array}{c}0.31 \\
(0.10)\end{array}$ & $\begin{array}{c}1.29 \\
(0.14)\end{array}$ & $\begin{array}{c}2.14 \\
(0.20)\end{array}$ & $\begin{array}{c}2.89 \\
(0.25)\end{array}$ \\
\hline
\end{tabular}

400

401 Table 5 - Item Response Theory item-parameter estimates for all 16 items on the SenPQ. 
402 Legend: $\alpha=$ discrimination parameter (slope); $\beta_{1}-\beta_{4}=$ threshold parameters (residuals). All

403 numbers in brackets are the bootstrapped standard error values. *=Residual unable to be 404 calculated.

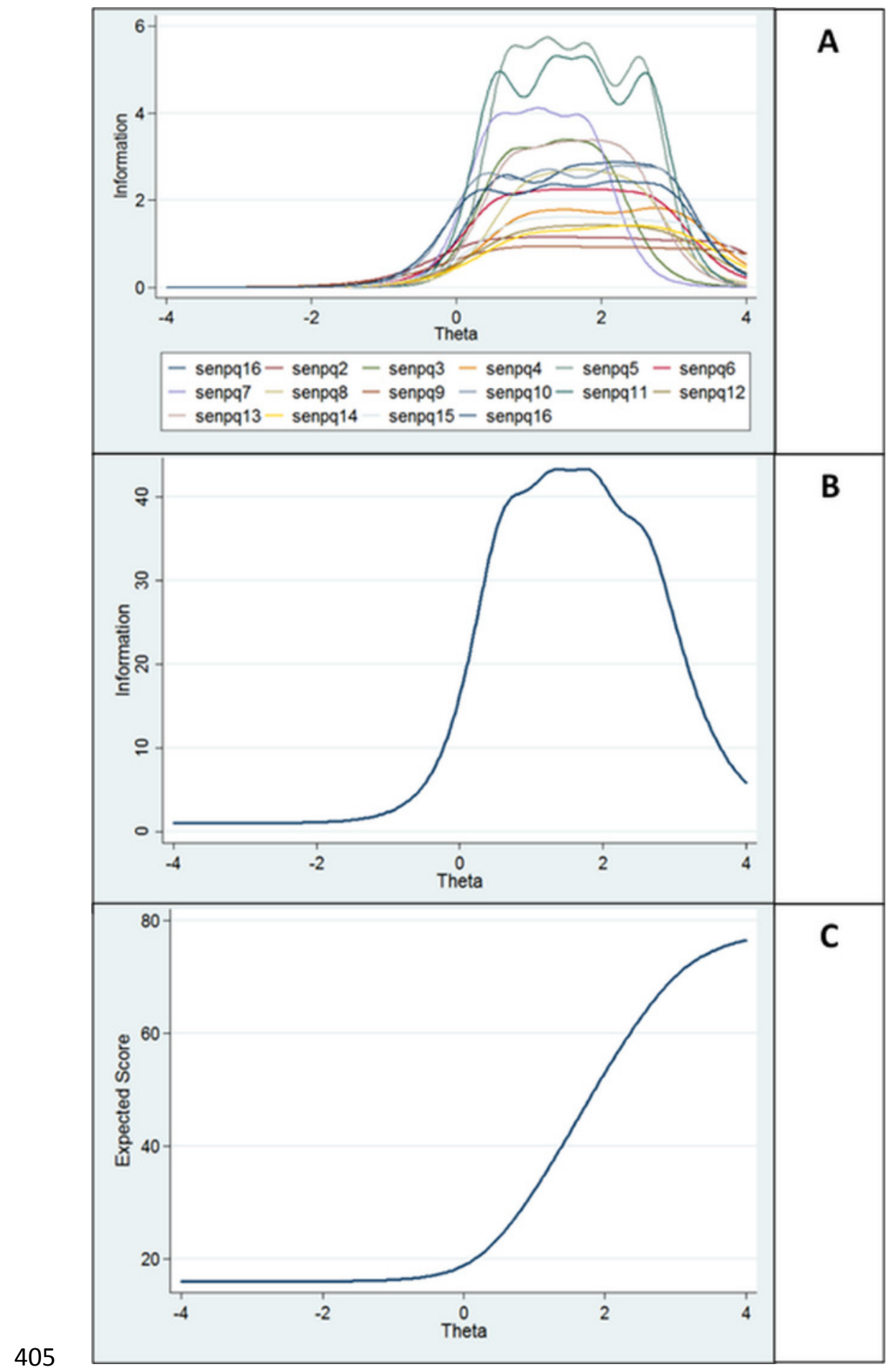


406

407

408

409

410

411

412

413

\begin{tabular}{ccccc}
\hline Measure & $\begin{array}{c}\text { Area Under } \\
\text { the Curve }\end{array}$ & Std. Error & \multicolumn{2}{c}{$95 \%$ CIs } \\
\hline SenPQ & $.655^{* * *}$ & .041 & .575 & .735 \\
$U E$ & $.592^{*}$ & .042 & .509 & .675 \\
$C D$ & .462 & .043 & .379 & .546 \\
$I A$ & .458 & .042 & .376 & .540 \\
$I N$ & .473 & .043 & .390 & .556 \\
O-LIFE & .490 & .043 & .406 & .574 \\
DSES & $.811^{* * *}$ & .034 & .745 & .878 \\
OEQ7 & $.656^{* * *}$ & .041 & .576 & .735 \\
WHO-5 & .547 & .043 & .464 & .630 \\
SIAS & .459 & .042 & .377 & .541 \\
\hline
\end{tabular}

414

415

416

417

418

419

420 Curve (C).

\section{ROC Analysis} Table 6 and Figure 3.

3
(positive) or non-religious (negative) identification.

Figure 2: Item Response Theory graphical analyses at the test and item level of the SenPQ.

Legend: Item Information Function (A), Test Information Function (B), and Test Characteristic

Data from the psychometric measures was entered into a ROC analysis to show they discriminated religious from non-religious groups over the extent of their score range. Results are displayed in

Table 6 - Receiver Operator Characteristic analysis of all measures predicting religious

Legend: SenPQ=Sensed Presence Questionnaire, O-LIFE = brief Oxford-Liverpool Inventory of Feelings and Experiences, $\mathrm{UE}=$ Unusual Experiences O-LIFE subscale, $\mathrm{CD}=$ Cognitive Disorganisation O-LIFE subscale, IA = Introvertive Anhedonia O-LIFE subscale, IN = Impulsive Non-Conformity O-LIFE subscale, OEQ-7 = Other Experiences Questionnaire, WHO-5 = World Health Organisation 5-item well- 
421 being questionnaire, DSES = Daily Spiritual Experience Scale, SIAS = Social Interaction Anxiety Scale.

422 Asymptotic significance: ${ }^{*} \mathrm{p}<0.05, * * * \mathrm{p}<0.001$. 


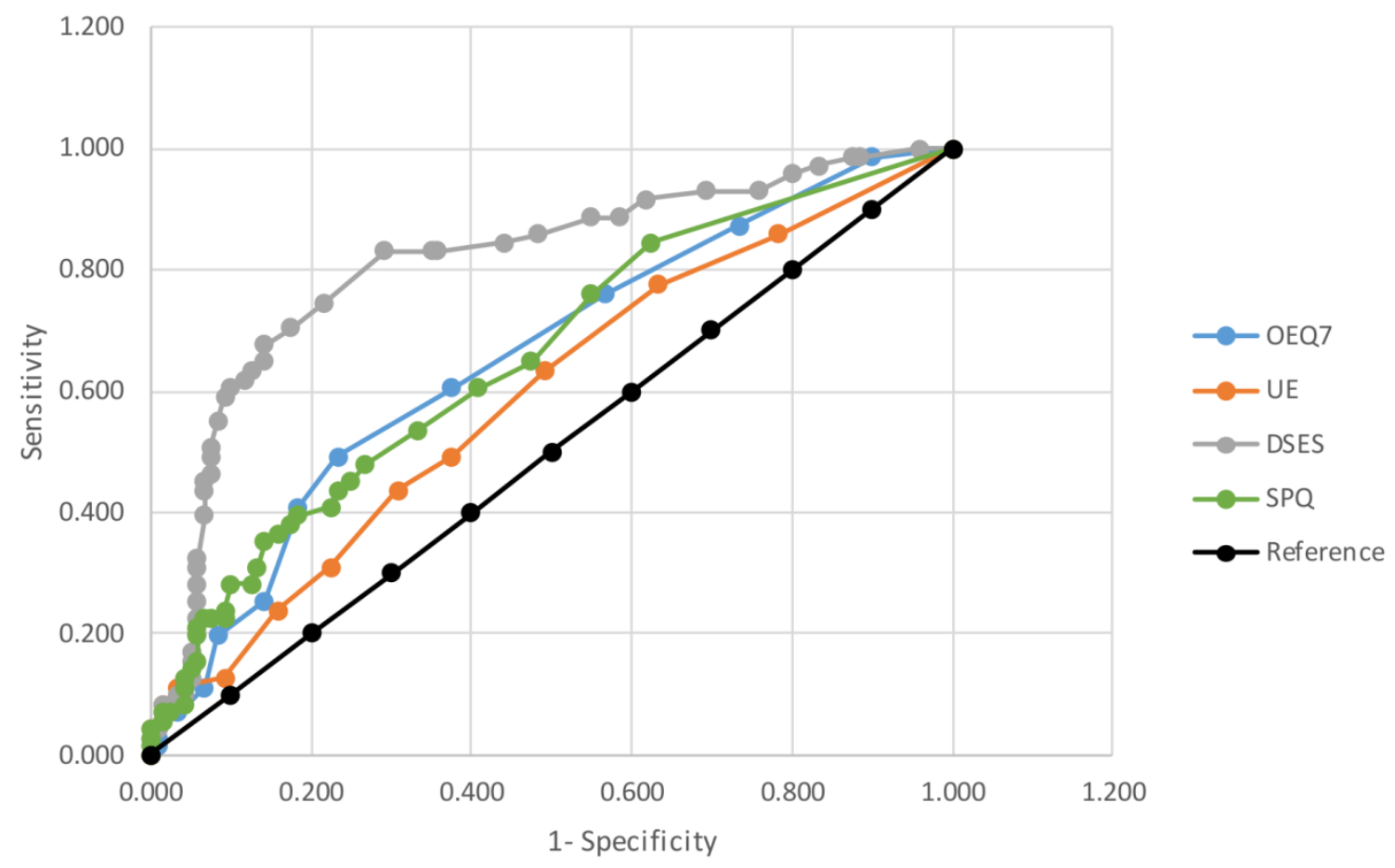

Figure 3 - Graph of receiver operating charactistic (ROC) curve for DSES, OEQ7, UE, and

SenPQ compared to the null reference in classifying religious and non-religious participants. Experiences Questionnaire, UE = Unusual Experiences O-LIFE subscale.

The most efficient total discriminator of religious and non-religious groups was the DSES. The SenPQ and OEQ7 were highly discriminant and perform almost identically. The Unusual Experiences subscale of the O-LIFE schizotypy scale discriminates between groups to a lesser extent, and all other scale show no significant discriminant ability. 


\section{Discussion}

435 This study involved the creation and initial validation of a 16-item sensed presence

436 questionnaire. In a general population sample, we demonstrated that the SenPQ is a reliable and

437 valid measure for measuring the experience of 'sensed presence'.

438

439 One of the clearest findings is that the experience of 'sensed presence' is quite common in the 440 general population, even among those who profess no religious affiliation. However, the

441 experience was more commonly reported by people who either classify themselves as having a

442 specific religion or who score more highly on a measure of daily spiritual experience, as was

443 predicted from previous research (Luhrmann and Morgain, 2012; Luhrmann, 2012; Granqvist et

444 al., 2005; Granqvist and Larsson, 2006).

However, considering that the experience of sensed presence has previously been reported in the 447 context of various states and conditions outside of a religious framework, including sleep disorders, neurological conditions, drug use, and intense physiological and emotional stress, we hope that the Sensed Presence Questionnaire to be useful across a range of presentations and this needs to be a focus for future validation studies.

451

452 Scores on the Sensed Presence Questionnaire showed a strong association not only with social 453 imagery and spiritual experience but also, selectively, with the unusual experience subscale of 454 the O-LIFE schizotypy scale, suggesting a link with hallucinatory and magical thinking 455 experiences on the psychosis continuum (Mason and Claridge, 2006). It has been argued

456 previously (Bell et al., in press) that the positive symptoms of psychosis involve, at least in part, 
457 the atypical activation of social cognitive systems for representing others, and we hypothesis that

458 the sensed presence experience may represent a state of minimal social agent representation.

459 Notably, the association with the O-LIFE scales was selective and there was no marked

460 relationship between sensed presence experience and other aspects of schizotypy that don't

461 represent hallucinatory experience. The fact that there was no association with social anxiety or

462 general well-being may suggest, measurement error aside, that the sensed presence experience

463 may reflect a form of minimal social agent representation which is heightened in people who

464 have higher levels of hallucinatory experience and is not just social anxiety-related

465 hypervigilance.

467 Two factors emerged from the factor analysis that were interpreted as 'benign' and 'malign',

468 echoing reports from the literature on differing emotional valence of sensed presence experiences

469 (Alderson-Day, 2016). Although seemingly a good conceptual fit to previous reports, it is worth

470 sounding a note of caution. Firstly, the factor analyses were exploratory and a confirmatory

471 factor analysis needs to be conducted on an independent sample before the concept of positively

472 and negatively valenced sensed presence experiences as distinct latent variables in the general

473 population can be accepted with confidence. Furthermore, the study was conducted with a

474 sample where members of religious groups were specifically invited to allow for a strong

475 comparison. We are aware that this may have over-represented people with benign sensed

476 presence experiences and a more representative sample of the general population is needed to be

477 sure the factor structure can be generalised. It is also likely that in people with associated

478 medical conditions, sensed presence experiences may arise from an impact on specific social

479 neurocognitive process and these may be quite different in terms of structure. 
481 Although our sample was diverse in terms of ethnicity, religion, and age, it also over-sampled

482 people with higher levels of education. Considering this, further validation needs to be conducted

483 using methods that are more likely to yield samples that are representative of the general 484 population.

486 Additionally, questionnaires were presented to the sample in a fixed order and it is possible that 487 order effects may have had an influence on responding via response bias. It is also worth bearing 488 in mind that when enquiring about experiences related to mental health and religion, social

desirability-related response biases need to be considered. While we assume that the paradigm used here, an anonymously completed online study, would be among the least subject to direct social desirability bias, we are aware that these areas have strong social stereotypes attached to them and internalised biases may be potential influences. Future studies could balance presentation order and use social desirability measures to exclude or adjust for these possible effects.

\section{Conclusions}

From the data presented here, the Sensed Presence Questionnaire (SenPQ) appears a reliable and valid measure of the 'sensed presence' experience. Initial principal components analyses suggest that the SenPQ may comprise of two factors, malign and benign presence. We hope the scale will be subject to further validation studies and will allow the 'sensed presence' experience to be investigated in a range of conditions. 


\section{References}

505 Alderson-Day B. 2016. The silent companions. The Psychologist, 29: 272-275.

506

507

508

509

510

511

512

513

514

515

516

517

518

519

520

521

522

523

524

525

526
Arzy S, Schurr R. 2016. "God has sent me to you”: Right temporal epilepsy, left prefrontal psychosis. Epilepsy \& Behavior, 60: 7-10.

Barbosa PCR, Giglio JS, Dalgalarrondo P. 2005. Altered states of consciousness and shortterm psychological after-effects induced by the first time ritual use of ayahuasca in an urban context in Brazil. Journal of Psychoactive Drugs, 37: 193-201.

Bell V, Halligan PW, Ellis HD. 2006. The Cardiff Anomalous Perceptions Scale (CAPS): A new validated measure of anomalous perceptual experience. Schizophrenia Bulletin, 32: $366-77$.

Bell V, Mills KM, Modinos G, Wilkinson S. In press. Rethinking Social Cognition in Light of Psychosis: Reciprocal Implications for Cognition and Psychopathology. Clinical Psychological Science

Bland JM, Altman DG. 2015. Statistics notes: bootstrap resampling methods. BMJ, 350: h2622.

Blom JD. 2010. A Dictionary of Hallucinations. London: Springer.

Brugger P, Regard M, Landis T. 1996. Unilaterally felt "presences”: the neuropsychiatry of one's invisible doppelganger. Neuropsychiatry, Neuropsychology, and Behavioral Neurology, 9: 114-122.

Cattell RB. 1966. The scree test for the number of factors. Multivariate Behavioral Research, 1: 245-276.

Cheyne JA. 2001. The Ominous Numinous. Sensed Presence and 'Other' Hallucinations. Journal of Consciousness Studies, 8:133-150. 
527 Cheyne JA, Newby-Clark IR, Rueffer SD. 1999. Relations among hypnagogic and hypnopompic experiences associated with sleep paralysis. Journal of Sleep Research, 8: 313-317.

Cheyne JA, Girard TA. 2007. Paranoid delusions and threatening hallucinations: a prospective study of sleep paralysis experiences. Consciousness and Cognition, 16: 959-974. factor structure of 'schizotypal 'traits: a large replication study. British Journal of Clinical Psychology, 35: 103-115.

Cronbach LJ. 1951. Coefficient alpha and the internal structure of tests. Psychometrika, 16: 297-334.

Eckblad M, Chapman LJ. 1983. Magical ideation as an indicator of schizotypy. Journal of Consulting and Clinical Psychology, 51, 215-225.

Ellison CG, Fan D. 2008. Daily spiritual experiences and psychological well-being among US adults. Social Indicators Research, 88: 247-271.

542 Emberston, S.E. \& Reise, S.P. (2000) Item response theory for psychologists. Lawrence Erlbaum Associates, Mahwah, NJ (2000) presence in Parkinson's disease. Journal of Neurology, Neurosurgery \& Psychiatry, 82:1219-24. presence and mystical experiences are predicted by suggestibility, not by the 
application of weak complex transcranial magnetic fields. Neuroscience Letters, 379:

550 1-6.

551 Granqvist P, Larsson M. 2006. Contribution of religiousness in the prediction and

552

553

554

555

556

557

558

559

560

561

562

563

564

565

566

567

568

569

570 interpretation of mystical experiences-activation of religious schemas. Journal of Psychology, 140: 319-327.

Hay D. 1979. Religious experience amongst a group of post-graduate students: A qualitative study. Journal for the Scientific Study of Religion, 18:164-182.

Hay D, Morisy A. 1978. Reports of ecstatic, paranormal, or religious experience in Great Britain and the United States: A comparison of trends. Journal for the Scientific Study of Religion, 17:255-268.

Horn JL. 1965. A rationale and test for the number of factors in factor analysis. Psychometrika, 30: 179-185.

Husain A, Singh R, Khan SM, Khan S (2016) Psychometrics and Standardization of the Hindi Adaptation of the Daily Spiritual Experience Scale. Clinical and Experimental Psychology, 2: 117.

James W. 1902. The Varieties of Religious Experience. United States: Harvard University Press.

Jaspers K. 1913 / 1963. General Psychopathology. Manchester University Press. Jaynes J. 2000. The Origin of Consciousness in the Breakdown of the Bicameral Mind. London: Houghton Mifflin Harcourt. Jung CG. 1969. The Archetypes and the Collective Unconscious. Princeton: Princeton University Press. 
571 Kass JD, Friedman R, Leserman J, Zuttermeister, PC, Benson H. 1991. Health outcomes and

572

573

574

575

576

577

578

579

580

581

582

583

584

585

586

587

588

589

590

591

592 a new index of spiritual experience. Journal for the Scientific Study of Religion, 30: $203-211$.

Kim SH, Martin BJ, Nolty AT. 2016. The Factor Structure and Measurement Invariance of the Daily Spiritual Experiences Scale. The International Journal for the Psychology of Religion, 26, 240-251.

Kurian AG, Currier JM, Rojas-Flores L, Herrera S, \& Foster JD. 2016. Meaning, Perceived Growth, and Posttraumatic Stress Among Teachers in El Salvador: Assessingthe Impact of Daily Spiritual Experiences. Psychology of Religion and Spirituality, 8: 289-297.

Landtblom AM. 2006. The "sensed presence": an epileptic aura with religious overtones. Epilepsy \& Behavior, 9: 186-188.

Luhrmann TM, Morgain R. 2012. Prayer as inner sense cultivation: An attentional learning theory of spiritual experience. Ethos, 40:359-389.

Luhrmann TM. 2012. When God Talks Back: Understanding the American Evangelical Relationship with God. London: Random House.

Luhrmann TM. 2013. Talking back about When God talks back. HAU, 3: 389-98.

Mason O, Linney Y, Claridge G. 2005. Short scales for measuring schizotypy. Schizophrenia Research, 78: 293-6.

Mattick RP, Clarke JC. 1998. Development and validation of measures of social phobia scrutiny fear and social interaction anxiety. Behaviour Research and Therapy, 36: $455-470$. 
593

594

595

596

597

598

599

600

601

602

603

604

605

606

607

608

609

610

611

612

613

614

615
Nielsen T. 2007. Felt presence: Paranoid delusion or hallucinatory social imagery? Conscious and Cognition, 16: 975-983.

O’Connor BP. 2000. SPSS and SAS programs for determining the number of components using parallel analysis and Velicer's MAP test. Behavior Research Methods, Instruments \& Computers, 32: 396-402.

Patil, Vivek H., Surendra N. Singh, Sanjay Mishra, and Todd Donovan (2008), "Efficient Theory Development and Factor Retention Criteria: A Case for Abandoning the 'Eigenvalue Greater Than One' Criterion,' Journal of Business Research, 61 (2), $162-170$.

Samejima, F. (1969). Estimation of latent trait ability using a response pattern of graded scores. Psychometrika Monograph Supplement. no. 17

Solomonova E, Nielsen T, Stenstrom P, Simard V, Frantova E, Donderi D. 2008. Sensed presence as a correlate of sleep paralysis distress, social anxiety and waking state social imagery. Consciousness and Cognition, 17: 49-63

Steffen E, Coyle A. 2011. Sense of Presence Experiences and Meaning-Making in Bereavement: A Qualitative Analysis. Death Studies, 35: 579-609

Suedfeld P, Mocellin JS. 1987. The "Sensed Presence" in Unusual Environments. Environment and Behavior, 19: 33-52.

Tellegen A, Atkinson G. 1974. Openness to absorbing and self-altering experiences (“"absorption”), a trait related to hypnotic susceptibility. Journal of Abnormal Psychology, 83: 268.

Thompson, C. 1982. Anwesenheit: Psychopathology and clinical associations. British Journal of Psychiatry, 141: 628-630. 
616 Topp CW, Østergaard SD, Søndergaard S, Bech P. 2015. The WHO-5 Well-Being Index: a 617 systematic review of the literature. Psychotherapy and Psychosomatics, 84: 167-76.

618 Trimble M, Freeman A. 2006. An investigation of religiosity and the Gastaut-Geschwind 619 syndrome in patients with temporal lobe epilepsy. Epilepsy \& Behavior, 9: 407-414. 620 Underwood LG. 2011. The daily spiritual experience scale: overview and results. Religions, $621 \quad 2: 29-50$.

622 Underwood LG, Teresi JA. 2002. The daily spiritual experience scale: development, 623 theoretical description, reliability, exploratory factor analysis, and preliminary construct validity using health-related data. Annals of Behavioral Medicine, 24: 2233.

626 World Health Organization. 1998. Well-Being Measures in Primary Health Care. The DEPCAR Project. Copenhagen: WHO Regional Office for Europe.

628 Woods A, Jones N, Alderson-Day B, Callard F, Fernyhough. 2015. Experiences of hearing 629 voices: analysis of a novel phenomenological survey. Lancet Psychiatry, 2: 323-331. 